\title{
Mud-volcanic deposits of methane gas hydrates in the Black Sea
}

\author{
Yevgeny Shnyukov ${ }^{1}$,Volodymyr Kobolev ${ }^{2 *}$, and Valentina Yanko ${ }^{3}$ \\ ${ }^{1}$ National Academy of Sciences of Ukraine, Center of Problems of Marine Geology, Geoecology and \\ Sedimentary Ore Formation, 55b Oles Gonchar St, 01054, Kyiv, Ukraine \\ ${ }^{2}$ National Academy of Sciences of Ukraine, Institute of Geophysics, 32 Palladina Ave., 03142, Kyiv, \\ Ukraine \\ ${ }^{3}$ Odessa I.I. Mechnikov National University, Department of Physical, Marine Geology and \\ Paleontology, 2 Shampansky Lane, 65058, Odessa, Ukraine
}

\begin{abstract}
This paper discusses the formation of a special mud-volcanic type of gas hydrate accumulation in the deep-water part of the Black Sea. The main conclusions are based on the results of geological and geophysical studies of mud volcanoes carried out in the course of numerous scientific cruises between 1970-2015. Comparison of the Black Sea submarine mud volcanoes with their on-land analogues indicates the possible use of compensatory depressions, called "recessed synclines", accompanying mud volcanoes, which is revealed in the course of prospecting and exploration of mineral deposits. In the sea they are represented by ring deposits of methane gas hydrates.
\end{abstract}

\section{Introduction}

The Black Sea basin holds great promise of new non-traditional energy sources for the Black Sea countries and most of Europe as well due to the presence of huge methane resources stored in gas hydrates beneath the sea floor. The amount of methane is estimated at between 25 and 49 trillion $\mathrm{m}^{3}$, which is several times bigger than known gas reservoirs on Earth. The presence of methane is evident from outbursts of submarine mud volcanoes (MV) that commonly contain ice-like aggregates of gas (largely methane) hydrates as well as many high-intensity gas seeps and gas clouds that release huge quantities of methane, e.g., 4.95 to $5.65 \mathrm{Tg} \mathrm{yr}^{-1}$ into the water column.

The area of the Black Sea suitable for gas hydrate formation is evaluated at $288100 \mathrm{~km}^{2}$, representing about $68 \%$ of the total Black Sea or almost $91 \%$ of the deep-water basin; the volume of gas hydrates has been estimated at $4.8 \mathrm{~km}^{3}$ corresponding to $0.1-1 \cdot 10^{12} \mathrm{~m}^{3}$ of free methane [1]. The main component of the Black Sea gas hydrates is methane. Within MVs, its concentration ranges between 93.3 and $99.98 \%$, the rest is represented by heavy and light methane homologues [2].

Due to metastability and specific bedding conditions, the production of gas hydrates is very problematic and, rather, refers to the future technologies. Nevertheless, due to the limited hydrocarbon reserves in Ukraine, gas hydrates of the Black Sea can be of great importance.

${ }^{*}$ Corresponding author: kobol@igph.kiev.ua 
Since geological and geophysical studies of methane gas hydrates are quite expensive and complex, search criteria are needed to narrow the research areas. Most often, accumulations of gas hydrates are confined to the continental slope, fault zones, and river flow cones. Several types of gas hydrates can be distinguished. One of them is associated with submarine mud volcanoes (MV). This type was first noticed in mud volcanic breccia of submarine MVs located on the bottom of the South Caspian Sea [3, 4].

The formation of this type of gas hydrate is associated with filtration of gases or gassaturated deep fluids through the thermobaric stability zone within MVs. This can be exemplified by distribution of the temperature field in submarine MV Haakon Mosby (Norwegian Sea, water depth 1250-1260) where 17 of 30 sampled stations recovered gas hydrate aggregates [5]. The distribution of methane gas hydrates has ring-shape zoning. This is most likely due to the outgoing deep fluid flow enriched with methane and temperature conditions created by it along the vent (Fig. 1).

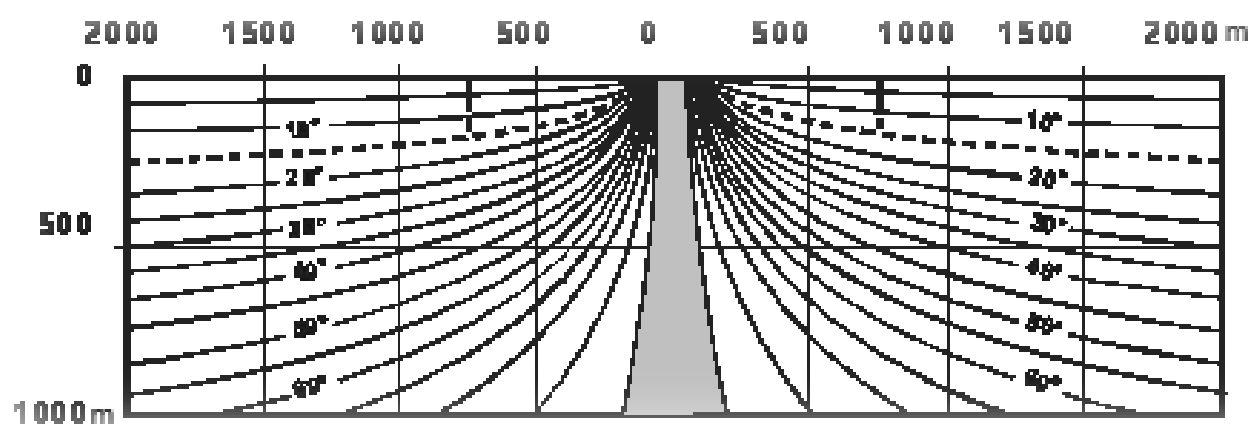

Fig. 1. Schematic distribution of isotherms along the vent of the submarine MV Haakon Mosby; modified by Soloviev [5]. Discontinuous horizontal isotherms correspond to the bottom of the gas hydrate stability zone, vertical - to the boundaries of gas hydrate distribution.

There are no methane gas hydrates in the MV vent. Instead, there is a circle in the mud volcanic breccia with a radius of $100 \mathrm{~m}$, where the temperature reached $15.4^{\circ} \mathrm{C}$ (compared to $8^{\circ} \mathrm{C}$ of the bottom water). Within $200 \mathrm{~m}$ from the MV center, the amount of methane gas hydrates reaches its maximum, exceeding $20 \%$ of the host rock (breccia) right at the sea bottom, while the saturation of breccia decreases with depth. With distance from the center, the upper boundary of gas hydrate precipitation deepens.

The outer boundary of gas hydrates is fixed at a distance of $750 \mathrm{~m}$ from the MV center and is determined by the intensity of the diffusing gas. The main building material for precipitation of methane gas hydrates is a fluid of low salinity (13.3 psu compared to 19.7 psu of sea water). According to Soloviev [5], between 1 and $10 \%$ of methane entering the hydrate formation zone is stabilized in gas hydrates.

Using geological and geophysical observations, it is difficult to evaluate gas hydrate saturation of sediments in the vicinity of underwater MVs. Numerical modeling is needed. Suetnova [6] considers the filtration mechanism of gas hydrate precipitation in bottom sediments within the zone of their thermobarimetric stability as more powerful compared to that of diffusion. Her calculation results indicate that the maximum rate of hydrate precipitation is $\sim 3 \%$ of the total pore space in sediments over 1000 years (sediment permeability $k_{0}=10-15 \mathrm{~m}^{2}$, temperature gradient $0.05^{\circ} \mathrm{m}^{-1}$, and depth of the supplying reservoir $1000 \mathrm{~m}$ from the bottom surface). According to [7], the calculated rate of gas hydrate precipitation significantly exceeds their rate in water areas of passive continental margins, where hydrate saturation is only the first percents and the rate of gas hydrate accumulation is estimated as about $1 \%$ over 105 years. As such, the speed of gas hydrate precipitation in the vicinity of submarine MVs due to filtration of gas-saturated pore fluid 
above the MV reservoir (diapir) is sufficient for the formation of significant gas hydrate accumulation over a period of several thousand years.

In the study of aquatic gas hydrates, geothermal investigations are essential. This includes: in-situ measurements of absolute temperatures and thermal conductivity of bottom sediments in order to calculate the heat fluxes, and elaboration of the thermobaric models for the development of gas hydrate zoning. Analysis of the processes of formation / destruction / stability of gas hydrates also requires consideration of possible changes in thermodynamic conditions over time, changes that are caused by physicochemical processes in the sediments as well as variations in the temperature of overlying water, sealevel changes, etc. Below the shelf, the temperature of bottom sediments ranges between 8.7 and $9.2^{\circ} \mathrm{C}$, increasing down the sediment sequence with a geothermal gradient of $50 \mu \mathrm{K} / \mathrm{m}$ on average. Based on these data as well as on the results of studying the equilibrium of gas hydrate-containing systems, one can conclude that the PT-conditions allow the existence of methane gas hydrates at water depths below $600-650 \mathrm{~m}$. With increasing sea depth, the thickness of the gas hydrates precipitation zone increases to $350-500 \mathrm{~m}$ in the deep part of the basin.

In the areas with a low heat flux $\left(25-30 \mathrm{~mW} / \mathrm{m}^{2}\right)$, the thickness of the gas hydrate layer reaches $350-400 \mathrm{~m}$. Under a heat flux of $40 \mathrm{~mW} / \mathrm{m}^{2}$, the thickness of the gas hydrate layer decreases to $200-250 \mathrm{~m}$; under $60 \mathrm{~mW} / \mathrm{m}^{2}$, the gas hydrate layer is not thicker than a few tens of meters; under abnormally high heat flux $\left(80-100 \mathrm{~mW} / \mathrm{m}^{2}\right)$, the gas hydrate layer is absent. This shows that the lower the heat flux, the thicker the gas hydrates layer and vice versa. As such, the most favorable thermobaric conditions for the stable formation of gas hydrates can exist in the deep part of the Black Sea only [8].

Similar to MV Haakan Mosby, one can assume the existence of ring-shaped gas hydrate deposits around MVs in the deep part of the Black Sea within the compensatory subsiding structures called recessed synclines [9].

Unfortunately, for the Black Sea, there are no data yet to delineate the deposits by the concentration of gas hydrates in the sediments. One can only assume a decrease in the saturation of sediments with gas hydrates with distance from the mud volcanic vents. But to delineate their clear boundaries is still not possible because it is unclear at what concentration of gas hydrates their extraction from the rock is possible. All this remains to be clarified. It should be remembered that a piece of discovered gas hydrate is still not its deposit or not even evidence of a gas hydrate formation zone.

The main goal of the paper is to provide insight into the formation of gas hydrates in submarine MVs of the Black Sea. The work is based on the results of geological and geophysical studies of MVs performed during 1970-2015 [9, 10].

\section{Structural-tectonic position of MVs of the Black Sea}

About $80 \mathrm{MVs}$ are known today in the Black Sea. Most of them are localized in deep water, but some of them have been found at relatively shallow depths as well [11] (Fig. 2). Their distribution over the area is not the same: Sorokin Trough - $20 \mathrm{MVs}$, WBSD $11 \mathrm{MVs}$, Tuapse and Giresun depressions -8 and 5 MVs, respectively, Shatskiy Ridge 7 MVs, Kerch-Taman Trough - 3 MVs, etc. No single MV has been recorded so far within the EBSD. The MVs were always covered by a thick layer of sea water. Although the Black Sea level has changed repeatedly and quite significantly, for example, $-120 \mathrm{~m}$ bpsl at the Last Glacial Maximum (LGM) [12], the deep part of the basin was not affected by these fluctuations.

Most of MVs have diverse isometric, or elongated cone-shaped form on the sea bottom. Their diameter at the base varies between a few hundred meters and several kilometers. For example, in the WBSD, the base of MVs reaches $1.5-2.5 \mathrm{~km}$, and even $4 \mathrm{~km}$ in diameter. 


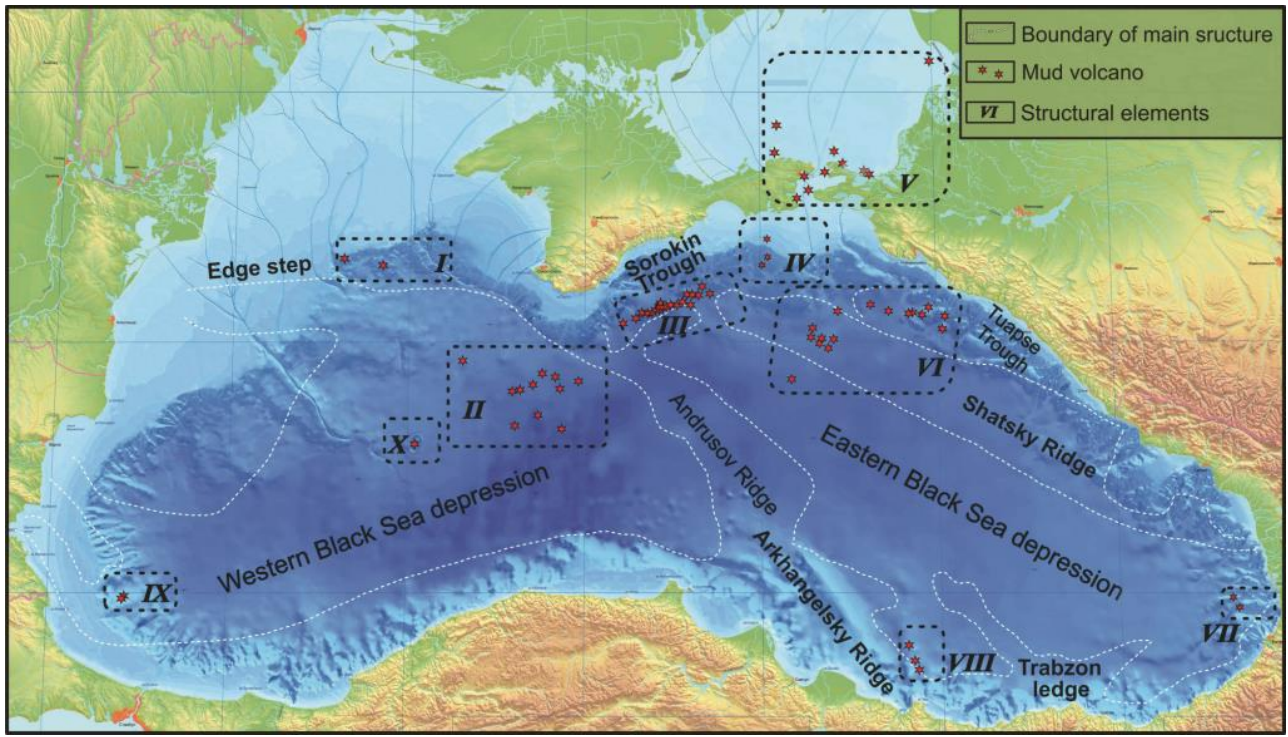

Fig. 2. Map of the Black Sea showing the major geological morphostructures and the groups of mud volcanoes: I - Northwestern; II - Western; III - Sorokin Trough; IV - near Kerch (Kerch-Taman shelf and continental slope); V - Kerch Strait and the Sea of Azov; VI - Tuapse Trough; VII - Georgian; VIII - Turkish (Gerisunckiy Trough); IX - Bulgarian; X - Central [9].

Compared to their diameter, the height of MVs is relatively small, hardly exceeding $100 \mathrm{~m}$ even in the largest ones. As such, the MV slopes, as a rule, do not exceed a few degrees. Such insignificant steepness of submarine cones of MVs can be explained by the low density of mud volcanic breccia that in the course of explosion can spread over a distance of several $\mathrm{km}$. In the middle, MVs have craters that can grow to several tens of meters in diameter. In addition to the main crater, there are small secondary vents for eruption of liquid and gas components, which are called as salses and gryphons [13]. There are also MVs without cones, and there are also so-called "blind" MVs. The latter are represented by subvertical eruptive channels that do not reach the surface [14]. In geological section, the MVs usually have the form of a flat and often truncated cone. The cone is composed of mud volcanic breccia, the flows of which can include several generations of eruptions.

MVs are confined to deep faults that play a crucial role in the emergence and development of the Earth's crust deformations. In particular, MVs of the WBSD are located within the Odessa-Sinop Fault Zone (OSFZ) of mantle origin, which had a significant impact on the formation of the Black Sea megadepression as a whole. The OSFZ divides large tectonic blocks of the Earth's crust. It is traced parallel to the axis of the Central Black Sea uplift stretching from the East European platform to the Pontides [15].

The MVs are located in the epicenter of the Western Black Sea Rift active geodynamic development and, most importantly, above the OSFZ. The forming of hydrocarbon deposits in the areas of deep granite-free depressions, such as the WBSD, is explained by many researchers as a feeding of reservoirs by deep hydrocarbon fluids under the influence of fracture zones in the upper crust [16]. Migrating upwards, deep fluids are enriched with hydrocarbons that could form deposits if there were sufficiently strong impermeable rocks on their way. If there are tectonic fractures, the fluids rush to the surface forming gas seepages or MVs [17]. This can explain the location of MVs within the OSFZ of the WBSD, where impermeable sediment layers were most exposed to tectonic destructions. 


\section{Results and discussion}

The submarine MVs are characterized by repeated eruptions of huge volumes of gases, mud breccia, clastic material, and water. The scale of the eruptions has not yet been estimated, but it should be comparable with those on land. The eruptions have led to the creation of weakened zones in the depths near mud volcanoes due to the removal of sedimentary material. The dimensions of these weakened zones are proportional to the volume of ejected masses. Weakened zones express themselves in the surface relief of the area as peculiar lowlands that usually take the shape of oval depressions. The depressions of mud volcanoes that developed in the Neogene seas filled with sediments accumulated in accordance with the position of the MV within the marine basin - silts, sands, as well as carbonate and ferrous sediments. Over time, the sediments turned into clays, limestones, sands, iron ores, etc. These rocks imposed a heavy loading that exacerbated the downward depression, and in the process of subsidence, numerous discontinuities in the rocks occurred, which often merged into ring disturbances.

The lowering of the Earth's surface as a result of the removal of underlying sedimentary material is not a property unique to MVs. The same phenomenon occurs in real volcanoes that eject lava.

Such depressions are clearly manifested on the Kerch and Taman peninsulas where they have received the local name "recessed synclines". The total number of known recessed synclines is 39. Many of them contain layers of Kimmerian iron ore deposits in their section [9]. Undoubtedly, submarine MVs are also accompanied by recessed synclines formed on the sea floor. Their sedimentary thickness must be different from those on land. Most likely, they are filled with marine fine-grained sediments (clays) alternating with gas hydrates. This is because MVs constantly emit natural gas mixtures in the form of fountains of methane, carbon dioxide, hydrogen sulfide, etc. from somewhere in the center of their craters or in the weakened zones around the MVs, such as recessed synclines. There, at depths exceeding 600-700 m, and under favorable pressure and temperature conditions, these gases form gas hydrates of significant thickness. In fact, recessed synclines serve as traps for their accumulation. Therefore, recessed synclines can be used as indicators for the search and exploration of gas hydrates.

The development of subsidence phenomena can be observed on many MVs. Most likely, in the Black Sea, gas hydrate deposits are concentrated around the most powerful central vents of MVs, e.g., hypothetical recessed synclines [11, 18, 19]. This can be exemplified by the well-studied Haakan Mosby MV in the Norwegian Sea, discussed above. In the Black Sea, depending on the power of the gas flow through the central vents of MVs, the formation of different size deposits of gas hydrates is quite possible. It well may be that cones of breccias of submarine MVs are gas hydrate deposits that reach up to $150 \mathrm{~m}$ in height and $4 \mathrm{~km}$ in diameter. But it is unlikely that the mud breccia is the only concentration of gas hydrates; most likely, there are alternations of marine sediments and gas hydrate deposits.

In the course of numerous expeditions carried out by different organizations, gas hydrates were recovered by gravity cores in $60 \%$ of all studied MVs located below isobath 600-700 $\mathrm{m}$ (compensation depth of gas hydrate formation) [11, 20-24].

A sample of white monomineral gas hydrate $(5-7 \mathrm{~cm})$ was recovered by a $3-\mathrm{m}$ core within the Gerisunckiy Trough (Fig. 2) at a water depth $2850 \mathrm{~m}$ [25]. It is important that gas hydrates were present in different core intervals indicating the presence of gas hydrate deposition.

The appearance of methane gas hydrate aggregates is quite diverse. A.N. Stadnitskaya [26] considered the morphology of methane gas hydrate aggregates recovered from breccia of the MV "Odessa" (Sorokin Trough). The aggregates often form irregular tabular fragments up to $4 \mathrm{~cm}$ in size, most likely representing remnants of gas hydrate veins or interlayers. 


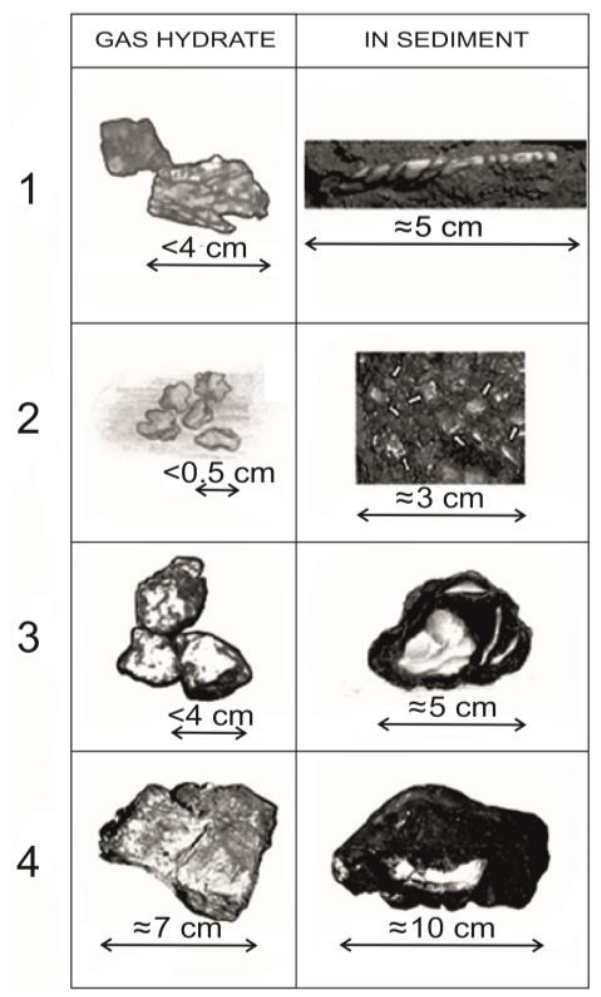

Fig. 3. Aggregates of gas hydrates, MV "Odessa", Sorokin Trough; after Stadnitskaya [26].
They also form massive tabular aggregates up to $7 \mathrm{~cm}$ in size, as well as "ice drops", which appear to be rounded aggregates no larger than $0.5 \mathrm{~cm}$ that surround large precipitates of gas hydrates. Most often, however, gas hydrates are precipitated in the form of small whitish crystals within the voids of mud volcanic breccia (Fig. 3).

Under current conditions, which the Black Sea basin inherited from the preceding Tethys, most submarine MVs presumably function episodically, at least since the Neogene up to the present time. In other words, recessed synclines should be filled with Neogene and Quaternary sediments, the periods of their accumulation during which mud volcanoes were active. It is difficult to imagine another mode of activity given the geological history of the Black Sea.

Apparently, all structures composed of mud volcanic breccia in deep parts of the Black Sea can represent potential deposits of gas hydrates. Surely, diffusion fluid flows enriched with gases and, as a consequence, precipitations of gas hydrates takes place all over in all types of sediment in the areas adjacent to MVs.

Their extraction requires special technological solutions and means.

A priority should be given to MVs functioning at least since the Neogene until now because, due to the long duration of their activity, there could highly favorable conditions not only in recessed synclines but in a much wider area (due to gas diffusion) for the development of thick layers of gas hydrate deposits. Since gas hydrates react quite clearly to changes in temperature, it is very likely that they may be not preserved in the Neogene geological sections. This question requires further study.

\section{Conclusions}

1. About 70 MVs are known today in the Black Sea. Most of them are localized in deep water. According to modern geophysical materials and data from studies of fluidogenic mineralization of breccia, MVs have a deep origin being seismically traced occasionally (e.g., MV Mantiynyy) to the Moho surface. As technical improvements proceed, the connection of MVs with the mantle will be clearly established.

2. The MVs were always covered by a thick layer of sea water. Although the Black Sea level has changed repeatedly and quite significantly, for example, $-120 \mathrm{~m}$ bpsl at the LGM, the deep part of the basin was not affected by these fluctuations. Repeated eruptions of huge volumes of gases, mud breccia, clastic material, and water make them comparable with on land MVs in Azerbaijan, Kerch-Taman, and other regions, led to formation of the accompanying structures called "recessed synclines" that are filled in with marine finegrained sediments alternating with methane gas hydrates. Numerous disturbances in rocks play as passways for ascending hydrocarbon fluids and most likely contribute significantly to precipitation of large deposits of gas hydrocarbons. 
3. The emergence and attenuation of underwater gas-mud discharge and precipitation of gas hydrates in the MVs is directly related to the geodynamic activity, which manifests itself in the increased seismicity of the Black Sea region.

5. In the Norwegian MV Haakon Mosby, the deposit of gas hydrates forms a giant "bagel". Similar ring-shaped deposits can be expected in the MVs of the Black Sea and the World Ocean as a whole. Their discovery is a matter of time.

6. In accordance with the outlined tasks, a proper planning and conduction of high resolution geological and geophysical investigation of the Black Sea MVs with subsequent experimental drilling within their boundaries is needed. It is the deep wells that will help to resolve the issue of the possibility to use gas hydrates of industrial production.

This work was conducted within the interdisciplinary program "Integrated monitoring, assessing and forecasting the dynamics of the marine environment and mineral resources in the Azov-Black Sea basin under increasing man-made load and climate change" with financial support from the National Academy of Sciences of Ukraine (2013-2015); the State Budget Themes \#539 "Study of the formation processes and spatial distribution of methane in the Black Sea and theoretical considerations of their influence on basin eco- and geosystems" (2016-2018), and \#590 "Development of predictive search criteria for hydrocarbon deposits in the Black Sea based on the theory of fluidogenesis" (2019-2021)" financed by the Ministry of Education and Science of Ukraine.

\section{References}

1. Vassilev, A., \& Dimitrov, L. (2002). Spatial and qualitative evaluation of methane hydrates in the Black Sea. Russian Geology and Geophysics, 43(7), 637-649.

2. Kruglyakova, R.P., Kruglyakova, M.V., \& Shevtsova, N.T. (2009). Geological and geochemical characteristics of natural manifestations of hydrocarbons in the Black Sea. Geologiya i Poleznye Iskopaemye Mirovogo Okeana, (1), 37-51.

3. Efremova, A.G., \& Gritschina, N.D. (1981). On the discovery of gas hydrates at the bottom of the South Caspian. Geologiya Nefti i Gasa, (2), 32-35.

4. Ginzburg, G.D., Gramberg, I.S., \& Guliev, I.S. (1988). Underwater-mud volcanic type of gas hydrate accumulations. DAN SSSR, 300(2), 416-418.

5. Soloviev, V.A. (2001). Gas hydrate content of the bowels of the World Ocean. Gazovaya Promyshlennost, (12), 19-23.

6. Suetnova, E.I. (2016). Accumulation of gas hydrates in the vicinity of underwater mud volcanoes Geofizicheskie Issledovaniya, 17(4), 39-48.

7. Davie, M.K., \& Buffett, B.A. (2001). A numerical model for the formation of gas hydrate below the seafloor. Journal of Geophysical Research: Solid Earth, 106(B1), 497-514. https://doi.org/10.1029/2000jb900363

8. Kutas, R.I., Kobolev, V.P., \& Tsvyashchenko, V.A. (1996). Geothermal aspects of the formation of gas hydrates in the Black Sea depression. Geofizicheskiy Zhurnal, 18(3), 20-27.

9. Shnyukov, E., \& Yanko-Hombach, V. (2020). Mud volcanoes of the Black Sea region and their environmental significance. Bern, Switzerland: Springer.

10. Shnyukov, E.F., Kobolev, V.P., \& Pasynkov, A.A. (2013). Gas volcanism of the Black Sea. Kyiv, Ukraine: Logos.

11. Shnyukov, E.F., Stupina, L.V., \& Rybak, E.N. (2015). Mud volcanoes of the Black Sea (Catalog). Kyiv, Ukraine: GNU OMGOR, Logos.

12. Yanko-Hombach, V. (2007). Controversy over Noah's Flood in the Black Sea: geological and foraminiferal evidence from the shelf. The Black Sea Flood Question: Changes in Coastline, Climate and Human Settlement, 149-203. https://doi.org/10.1007/978-1-4020-5302-3 7

13. Shnyukov, E.F. (2017). Mud volcanoes of the Black Sea as a search indicator for methane gas hydrates. Riga, Latvia: Laplambert Academic Publishing. 
14. Shnyukov, E.F., \& Kobolev, V.P. (2020). Blind mud volcanoes of the Black Sea. Geologiya $i$ Poleznye Iskopaemye Mirovogo Okeana, 16(2), 49-65.

15. Starostenko, V.I., Makarenko, I.B., \& Rusakov, O.M. (2010). Geophysical inhomogeneities of the Black Sea lithosphere megadepression. Geofizicheskiy Zhurnal, 32(5), 3-20.

16. Milanovsky, S.Yu., \& Nikolaevsky, V.N. (2012). Processes of transfer (migration) of cracks in the earth's crust (2012). Modern methods of seismic prospecting in the search for oil and gas fields in the conditions of complex structures "Seismo-2012", 1-8.

17. Dmitrievsky, A.N., \& Balanyuk, I.E. (2009). Gas hydrates of seas and oceans - a source of hydrocarbons of the future. Moscow, Russian Federation: LLC IRC Gazprom.

18. Gonchar, A.I., Pisanko, I.N., \& Sobisevich, L.E. (2004). Underwater mud volcanism of the AzovBlack Sea basin. Gidroakustichniy Zhurnal, (1), 70-83.

19. Gorchilin, V.A., \& Lebedev, L.I. (1991). On the signs of gas hydrates in the sedimentary layer of the Black Sea and the possible type of hydrocarbon traps. Geologicheskiy Zhurnal, (5), 75-81.

20. Bohrmann, G., Akarsu, E., \& Bar, A. (2011). Origin and distribution of methane and methane hydrates in the Black Sea - Cruise No. M84/2 (February 26 - April 02, 2011). Istanbul, Turkey, 59 p.

21. Bohrmann, G., Ivanov, M., Foucher, J.-P., Spiess, V., Bialas, J., Greinert, J., \& Zillmer, M. (2003). Mud volcanoes and gas hydrates in the Black Sea: new data from Dvurechenskii and Odessa mud volcanoes. Geo-Marine Letters, 23(3-4), 239-249. https://doi.org/10.1007/s00367003-0157-7

22. Ivanov, M.K., Limonov, A.F., \& van Weering, Tj.C.E. (1997). Comparative characteristics of the Black Sea and Mediterranean Ridge mud volcanism. Marine Geology, (132), 253-271. https://doi.org/10.1016/0025-3227(96)00165-X

23. Konyukhov, A.I., Ivanov, M.K., \& Kulnitsky, L.M. (1990). On mud volcanoes and gas hydrates in the deep-water regions of the Black Sea. Litologiya i Poleznye Iskopaemye, (3), 12-23.

24. Shnyukov, E.F., \& Kobolev, V.P. (2004). Geological and geophysical research in the $61^{\text {st }}$ cruise of the R/V "Professor Vodyanitsky" in the Black Sea. Geophisicheskiy Zhurnal, 26(6), 185-189.

25. Kruglyakova, R.P., Byakov, Y.A., Kruglyakova, M.V., Chalenko, L.A., \& Shevtsova, N.T. (2004). Natural oil and gas seeps on the Black Sea floor. Geo-Marine Letters, 24(3). https://doi.org/10.1007/s00367-004-0171-4

26. Stadnitskaya, A.N., \& Belenkaya, I.Yu. (2000). Composition and origin of hydrocarbon gases and their influence on diagenetic carbonate formation (Sorokin Trough, NE part of the Black Sea). Geologiya Chernogo i Azovskogo Morey, 155-163. 